\title{
La ficción, el relato y la construcción mítica del paisaje como herramientas activas de producción territorial
}

\author{
FICTION, STORY AND MYTHIC CONSTRUCTION OF LANDSCAPE AS ACTIVE TOOLS \\ FOR TERRITORIAL PRODUCTION
}

\begin{abstract}
A FICÇÃO, O RELATO E A CONSTRUÇÃO MÍTICA DA PAISAGEM COMO INSTRUMENTOS ATIVOS DE PRODUÇÃO TERRITORIAL
\end{abstract}

\author{
Marcos Castaings Bentancor *1 \\ mcastaings@hotmail.com
}

\begin{abstract}
Resumen
Este ensayo intenta establecer la pertinencia de una evolución en el protocolo de trabajo tradicional de las disciplinas de la arquitectura y el territorio, como consecuencia de la identificación de una serie de emergencias socio-culturales transformadoras (nuevos tópicos trascendentes) para, partiendo de su análisis genealógico, fundar las bases teóricas de una nueva mirada sobre la intervención en las primeras. Esta, alternativa a la visión de acento tecnificista vigente, privilegia las herramientas creativas sobre las diagnósticas y postula como base la construcción ficcional, la utilización del paisaje (entendido de manera compleja) como tejido conectivo del territorio (en lo social, cultural, estético, productivo, económico, ético, etc.) y el relato (storytelling) como herramienta fundamental y vehículo generador de posibles futuros, verosímiles y compartidos. Para esta ideación protocolar explora la historia de las construcciones mitológicas y épicas de lo intangible y de lo concreto (ciudad, geografía, paisaje) y las evoluciones de la construcción ficcional desde lo mítico y lo épico a lo icónico y temático. Ahonda en el rol de contar y la narración como práctica arquitectónica y territorial, desvelando sus herramientas y estudiando su posible migración disciplinar desde la literatura a la arquitectura, paisaje, urbanismo y ordenamiento. Finalmente, analiza la especificidad del territorio latinoamericano (de "reciente invención", dimensiones inusitadas, especificidades dispersas y variadas) y su innata condición de territorio relatado, como elementos indicativos de la oportunidad para el ensayo inicial de este nuevo método en el mencionado recorte territorial.
\end{abstract}

Palabras clave: paisaje, ficción, relato, territorio, storytelling

\footnotetext{
1 * Facultad de Arquitectura, diseño y urbanismo. Universidad de la República
}

Tekoporá ${ }^{\circledR}$. Centro Universitario de la Región Este. Universidad de la República (C) Castaings. (2021)

Este es un artículo de Acceso Abierto distribuido bajo licencia Creative Commons (CC BY NC 4.0) 


\begin{abstract}
The following essay attempts to establish the pertinence of a development in the traditional work protocol of the disciplines of architecture and territory, as a consequence of the identification of a series of transformative socio-cultural emergencies (new transcendent topics) in order to, from a genealogical analysis, found a theoretical base for a new way to look at interventions into these disciplines. As an alternative to the current technologically-accented vision, this approach favors creative tools over diagnostic ones, postulates fictional construction as basic, the use of landscape (understood in a complex way) as a connective tissue of territory (socially, culturally, aesthetically, productive, economic, ethical, etc.), and the idea of story (storytelling) as a fundamental tool and vehicle that generates possible, credible and shared futures. For this protocol ideation, this essay explores the history of mythological and epic constructions of the intangible and of the concrete (city, geography, landscape) and the evolutions of fictional construction from the mythical and epic to the iconic and thematic. It delves into the role of telling and narration as an architectural and territorial practice, unveiling its tools and studying its possible disciplinary migration from literature to architecture, landscape, urban planning and territorial ordinance. Finally, it analyzes the specificity of the Latin American territory (of 'recent invention', unusual dimensions, dispersed and varied specificities) and its innate condition of told and lettered territory, as indicative elements of the opportunity for the initial trial of this new method in the aforementioned territorial delimitation.
\end{abstract}

Keywords: landscape, fiction, story, territory, storytelling

\title{
Resumo
}

Este ensaio procura estabelecer a relevância de uma evolução no protocolo de trabalho tradicional das disciplinas de arquitetura e território, como consequência da identificação de uma série de emergências socioculturais transformadoras (novos tópicos transcendentes) para, com base na sua análise genealógica, encontraram as bases teóricas de um novo olhar sobre a intervenção nas primeiras. Esta, alternativa à visão do sotaque tecnológico atual, privilegia as ferramentas criativas em detrimento das diagnósticas e postula como base a construção ficcional, o uso da paisagem (entendida de forma complexa) como tecido conectivo do território (no social, cultural, estetico, produtivo, econômico, ético, etc.) e a história (storytelling) como uma ferramenta e veículo fundamental para a geração de futuros possíveis, críveis e compartilhados.Para esta ideação protocolar, explora a história das construções mitológicas e épicas do intangível e do concreto (cidade, geografia, paisagem) e as evoluções da construção ficcional do mítico e épico ao icônico $e$ temático. Mergulha na função de contar e a narração como uma prática arquitetônica e territorial, revelando suas ferramentas e estudando sua possível migração disciplinar da literatura para a arquitetura, paisagem, planejamento urbano e ordenamento. Por fim, analisa a especificidade do território latino-americano (de 'invenção recente', dimensões inusitadas, especificidades dispersas e variadas) e sua condição inata de território relatado, como elementos indicativos da oportunidade para o ensaio inicial deste novo método no corte 
territorial mencionado.

Palavras-chave: paisagem, ficção, território, relato, storytelling

\section{Introducción}

Para uno de esos gnósticos, el visible universo era una ilusión o (más precisamente) un sofisma

J.L. Borges “Tlön, Ucbar, Orbis Tertius” (1941)

Entretanto, Montevideo no existe. Aunque tenga más doctores, empleados públicos y almaceneros que todo el resto del país, la capital no tendrá vida de veras hasta que nuestros literatos se resuelvan a decirnos cómo y qué es Montevideo y la gente que la habita. (...) Es indudable que si lo hacen con talento, muy pronto Montevideo y sus pobladores se parecerán de manera asombrosa a lo que ellos escriban.

J.C. Onetti, Revista Marcha (1939)

Las últimas décadas del siglo pasado y primeras del presente han sido testigo de la emergencia en la consideración de los imaginarios colectivos como elementos centrales para la construcción del territorio. Sin embargo, el estudio de estas situaciones usualmente se ha entendido como un rastreo ex-post, como un proceso que, en el mejor de los casos, era interesante reconocer, documentar, pero nunca desentrañar verdaderamente más allá de sus consecuencias. Mucho menos pensarlo como una cuestión pasible de ser utilizada como herramienta para la producción activa del mismo. Esto ha sucedido, en parte, porque los estudios y las reflexiones acerca de estas temáticas siempre han provenido desde las ciencias sociales, no desde las disciplinas de la arquitectura, el paisaje, el urbanismo y planificación, históricamente lideradas por profesionales de formación arquitectónica.

Lo que se intenta resumir en el presente trabajo (ensayo que oficia de adelanto preliminar de una investigación mayor) es cómo el análisis más cuidadoso de la génesis de estos imaginarios podría descubrir las herramientas, las intencionales y las azarosas, que se han combinado para transformarlos en cuestiones de profunda productividad territorial, para a partir de allí 'aislarlas', identificando y perfeccionando posibles instrumentos de trabajo de cara a la configuración de un nuevo protocolo operativo, aplicable de manera a-escalar.

$\mathrm{Ni}$ bien se plantea este camino de indagación, una reflexión emerge a la superficie. Dos son los elementos (en su extensa diversidad de expresiones posibles) que se encuentran decididamente en la base de la construcción de todo imaginario: la ficción y el relato. Inspeccionados cuidadosamente estos son además, por su permanencia y recurrencia de aparición, las herramientas 
principales de la construcción histórica y por ende, inherentes a la condición humana. En este sentido, un rastreo medianamente sistemático de ejemplos pasados permitirá elaborar una taxonomía precaria de estas ficciones y relatos, rastreando sus sucesivas evoluciones estructurales y previsualizando sus posibles transformaciones futuras.

En definitiva, el documento plantea como hipótesis la posibilidad de pensar y desarrollar el proyecto a escala arquitectónica, paisajística, urbana y/o territorial (planificación) como una forma evolucionada, en tanto comprometida con un territorio o ámbito concreto, de la ficción compleja, en particular del relato. Reflexiona además sobre la posibilidad de desplazar el eje de trabajo del arquitecto, paisajista, urbanista y planificador desde la planificación o la confección de proyectos mediante los métodos tradicionales de diseño (plan, proyecto, etc.) a la elaboración de ficciones inacabadas, que sean expresables y expresadas mediante un relato, y que utilicen los primeros como herramientas accesorias.



Serie "El cuerpo alegórico de América" \#01 (2017)Paola Monzillo Dibujos en tinta pigmentada sobre papel de celulosa $300 \mathrm{gr}$., $24 \times 32 \mathrm{~cm}$. 
Para ello acepta provisoriamente hipótesis complementarias. Primero, que el componente ficcional es inherente a la conformación de las sociedades en sí mismas, y que ocupa un espacio central en la construcción de la identidad, que se da, de manera general y en los diferentes estratos sociales, fundamentalmente a partir de las artes y las ciencias y/o técnicas. Esa componente ficcional, imaginaria, es por el contrario a las creencias de la 'ciencia normal' del urbanismo, la planificación, la arquitectura y el paisaje contemporáneos, la base de la mayoría de los procesos exitosos de diseño multiescalar y planificación, desarrollo y gestión del territorio.

Segundo, que ese componente es, además de una cuestión que se puede rastrear a posteriori, una cuestión que se puede (y debe) generar (y/o concebir) con anterioridad, y este proceso está lejos de ser casuístico en la mayoría de las situaciones. Muy por el contrario, puede (y debe) ser un proceso intencionado, guiado y construido participativamente, y es el rol central del creador / planificador / gestor imaginar la impronta inicial (argumento), para luego fijar las bases de este proceso y reglamentar las instancias de participación.

Tercero, que la construcción de relatos explicativos es el método natural de generación de estos procesos, y que, por su especificidad creativa, la literatura debe ser el ejemplo de aprendizaje para esta función del creador / planificador / gestor. Esta, como expresión compleja de la ficción oral, posee instrumentos y herramientas de trabajo y exploración que pueden ser de utilidad transportadas a las disciplinas del territorio. Esas herramientas e instrumentos se pueden identificar mediante el análisis de casos, se pueden desplegar en un kit de trabajo, construyendo una mecánica abierta y no reduccionista, que no atente contra el carácter complejo de los procesos.

Finalmente, que estos instrumentos vendrían a sustituir a otros ya perimidos, complementando los todavía vigentes, y a constituir el núcleo de la nueva pulsión creativa, que encarna la principal arma democrática e inclusiva (por la baja tecnificación requerida para la participación), a la que vez optimista, desprejuiciada y comprometida para la gestión de las tareas disciplinarias.

Vale realizar, sin embargo, una aclaración que no por evidente deja de resultar necesaria. No es el objetivo del trabajo resumido en este documento la construcción y el postulado de una metodología de creación que sustituya integralmente a la actualmente convalidada. Muy por el contrario, la posible interacción de la alternativa de trabajo que se pretende estructurar, parte de la base de su posibilidad de simbiosis con los métodos usuales de acercamiento a la actividad creativa, facilitando estructuras conceptuales y marcos de verdad que ayuden a la evolución y concreción de las ideas de proyecto. Pretende entonces hacer visible otros focos de trabajo, establecer otros énfasis y descubrir otras miradas, que puedan ser utilizadas para fortalecer, tanto la estructura decisional general, como las definiciones puntuales (materiales) de los procesos creativos en las disciplinas del territorio. 


\section{Paisaje y territorio: Emergencia de nuevos tópicos trascendentes}

Se ha esbozado en la anterior introducción como un nuevo interés por los 'constructos' territoriales imaginarios se vincularía hipotéticamente con una actualidad histórica particular que se expresa en un acotado número de emergencias, que se resumirá en el presente documento en siete: la consideración de la variable temporal de una manera más compleja; la atención a la finitud de los recursos naturales; el foco en la cuestión social (a través de la valoración de las identidades locales y/o regionales y el énfasis en el desarrollo endógeno); el surgimiento de una nueva manera de mirar el patrimonio; la universalización del desplazamiento por intermedio de la socialización del turismo y la exacerbación de las migraciones; la recuperación de un estatus fundamental para la noción de belleza, ampliada y reformulada, y; el redescubrimiento del paisaje como una cuestión a revisitar y resignificar.

Las tres primeras temáticas, en su inmensa amplitud y generalidad, encarnan la toma de conciencia de la humanidad acerca de la delicada realidad socio ambiental sobre el planeta, y se vinculan con seguridad a una incipiente madurez evolutiva como especie. Así, tanto la reflexión a propósito del manejo del tiempo y su administración para la búsqueda de objetivos interpersonales concretos; la certeza de que nuestro devenir se encuentra circunscripto dentro de un ámbito planetario frágil que es prioridad salvaguardar; y la conciencia de que esa preservación debe enfocarse en el bien común de la humanidad en su conjunto son, naturalmente, diferentes caras de una misma moneda. Sus núcleos de interés son difusos y se encuentran profundamente interconectados.

Las tres siguientes, por el contrario, constituyen aristas notablemente más específicas del continuum temático referido. Si las anteriores se enmarcaban en una novedosa manera de concebir el mundo, estas tres se enfocan en las formas nuevas de percibirlo. Un mundo pleno de riquezas de todo formato y especie; vasto pero a la vez crecientemente accesible; colmado de episodios poseedores de una nueva forma de belleza. Son, como es comprensible, tópicos derivados en cierta forma de la interacción de las anteriores, pero no por ello carecen de cualidades características.

La última se vincula a la identificación de un nuevo concepto contemporáneo de paisaje, para el cual la ambigüedad constituye un elemento característico y definitorio. Se puede mapear cómo dicha condición ambigua, parcialmente inaprehensible, ha ido puliéndose mediante la incorporación de cada vez más registros, escalas y lecturas para terminar designando todo lo que refiere a la percepción del entorno físico y material del ser humano. A partir de dicho proceso es que este concepto ha de servir como soporte interactivo entre temáticas, como tejido conectivo entre emergentes. Su propia ambigüedad, derivada de la generalidad de los ámbitos, procesos y elementos que se pueden describir mediante el término, permite que este actúe como denominador común y espacio de interrelación entre una multiplicidad de disciplinas.

Pero se puede arriesgar todavía más. Desde su definición histórica la idea de paisaje está vinculada, más que con una realidad material (más que con la propia 
entidad), con la imagen mediatizada por el intelecto o los sentidos, con la percepción o perspectiva que de una realidad material construye un determinado individuo o conjunto de individuos. En otras palabras, con una construcción ficcional, intra o interpersonal. De esta manera el concepto mismo de paisaje trae implícito además el de ficción, tema central de la siguiente sección del presente documento.

\section{Ficción y territorio: Teoría y empirismo del acercamiento ficciona}

Como se explora en la tarea genealógica violentamente resumida en el punto anterior, la construcción ficcional del territorio no es algo meramente vinculado a las emergencias contemporáneas en él citadas. Por el contrario, la presencia de mitos tangenciales a las mismas, se perciben en todos los micro relatos que dan cuerpo a las propias emergencias anteriores. La construcción ficcional tampoco constituye, atendiendo a las mismas evidencias, una novedad contemporánea sino una práctica que se puede remontar a los albores mismos de la humanidad.

Las construcciones mitológicas y épicas de lo intangible, en particular las identidades y las nacionalidades encuentran sus antecedentes en la construcción ficcional de la pertenencia, desde la herencia dinástica, la cultura sagrada y el linaje. En todas ellas, la función del relato explicativo es fundamental. Toda la organización sociocultural en la que estamos inmersos, y con la cual sentimos cierto grado de identificación, constituye una construcción cultural imaginaria, históricamente edificada sobre la base de ciertos artilugios (o artefactos) ficcionales. Las iniciales culturas sagradas y estructuras dinásticas han evolucionado en las nacionalidades, resignificado en muchos casos los linajes originarios, y en otros generado unos nuevos (si bien ya no basados en la descendencia primigenia de los dioses, pero sí de unos nuevos héroes), edificados mediante los mismos mecanismos ancestrales. Pero a la vez se han multiplicado, en operaciones homotéticas constructoras de idéntico sentido pero diferente escala, hacia la creación de las contemporáneas identidades: las locales, las macro-comunitarias, y las temáticas o sectoriales.

Pero si los mecanismos básicos se han mantenido, las demás características de los procesos de construcción ficcional de la pertenencia han sufrido modificaciones profundas. Por un lado se ha modificado el componente temporal de dichos procesos. Un proceso que, en el caso de la cosmogonía hinduista se construyó y mantuvo durante más de tres mil años, ha sido sustituido hoy (naturalmente que no en trascendencia) por la construcción de una identidad micro regional, que se desarrolla quizás en un par de décadas (si bien apelando a narraciones anteriores). La duración de las estructuras de pertenencia también se ha diversificado. Aceptando que todavía existen las de largo término, han surgido otras que desaparecen tan rápido como nacen y crecen.

También la condición multicapa de la pertenencia se ha modificado. Como se puede ver en multiplicidad de ejemplos como el del pueblo k'iche' guatemalteco, una cosmogonía se correspondía con una religión, una lengua y un territorio 
determinados. Un primer paso hacia esa simplificación ya se hace patente en las nacionalidades, para las cuales, tanto la religión como la lengua no son elementos imprescindibles. En las identidades locales este proceso se extrema, pasando los elementos significantes inclusive a cuestiones aparentemente triviales. En otras categorías de pertenencia, como las sectoriales, ni siquiera un territorio es necesario, sino simplemente un interés, una habilidad, un hobbie.

Las reflexiones desarrolladas en los párrafos anteriores permitirían arriesgar que, en primer lugar, la hipótesis de la productividad de las construcciones ficcionales como generadoras de estructuras de pertenencia no sólo se verifica sino que, aún más importante, es el mecanismo más común y casi el único por el cual estas estructuras se generan y fortalecen. En segundo lugar, que dichas estructuras se han alivianado progresivamente, haciéndose más abiertas y menos condicionadas, lo cual ha redundado en su multiplicación a diversas escalas y complejidades. Estas reflexiones alientan la posibilidad de afirmar que la posibilidad de la creación de pertenencia como una de las tareas operativas del urbanismo y el planeamiento puede resultar (al menos) verosímil dentro de esta evolución.

El elemento concreto, por otra parte, sea este ciudad, geografía o paisaje, también posee una historia de construcciones mitológicas y épicas. Más allá de sus (muchas veces) azarosas circunstancias y la concatenación de equívocos a partir de los cuales se ubicó, identificó y denominó a muchas de las regiones del planeta; la construcción ficcional también fue fruto de un pulso intencional, que buscaba concretar disímiles objetivos. Ellos estaban alternativamente en el futuro y el pasado, puesto que la construcción ficcional perseguía; tanto la expansión de los límites conocidos de la economía, la cultura y la religión hacia unas fronteras antes lejanas e inaprensibles; como la recuperación de las tierras antiguas y legendarias, que pervivían en la memoria colectiva de las civilizaciones. Una larga relación de episodios atestigua estas afirmaciones, desde los lugares legendarios ${ }^{2}$, la Venecia palladiana y análoga pintada por Canaletto, los grabados (vedutas purgadas) (Sing, 1996) del Plan para el Campo Marzio en Roma realizados por Piranesi, la invención de las ciudades invisibles (Calvino, 1972) que Marco Polo narrara a Kublai Khan, entre tantos otros.

Esta mecánica, en cierta medida automática, vinculada al descubrimiento y redescubrimiento mediante la estrategia combinada del andar y el fabular, comenzó a cejar en la medida en que los confines métricos del mundo se empezaron a precisar. Sin embargo, para una especie que había vivido en esa práctica desde su nacimiento, el otear de horizontes mal podría desaparecer. En su lugar cambió de signo, para convertir la construcción ficcional de tierras lejanas o legendarias en la materialización simbólica de las tierras cotidianas, escenario de la vida comunitaria. Así, intentó también andar el camino recorrido por las construcciones de la pertenencia, primero enfocadas en las grandes cosmogonías y luego trasladadas a las condiciones identitarias cercanas.

\footnotetext{
${ }^{2}$ Ver: (Brooke-Hitching, 1996); (De Tocqueville, 2015); (Eco,2013); (Guadalupi - Manguel, 2004); (Lanni, 2016); (Le Carrer, 2015); (Middleton, 2016); (Schalansky, 2011).
} 


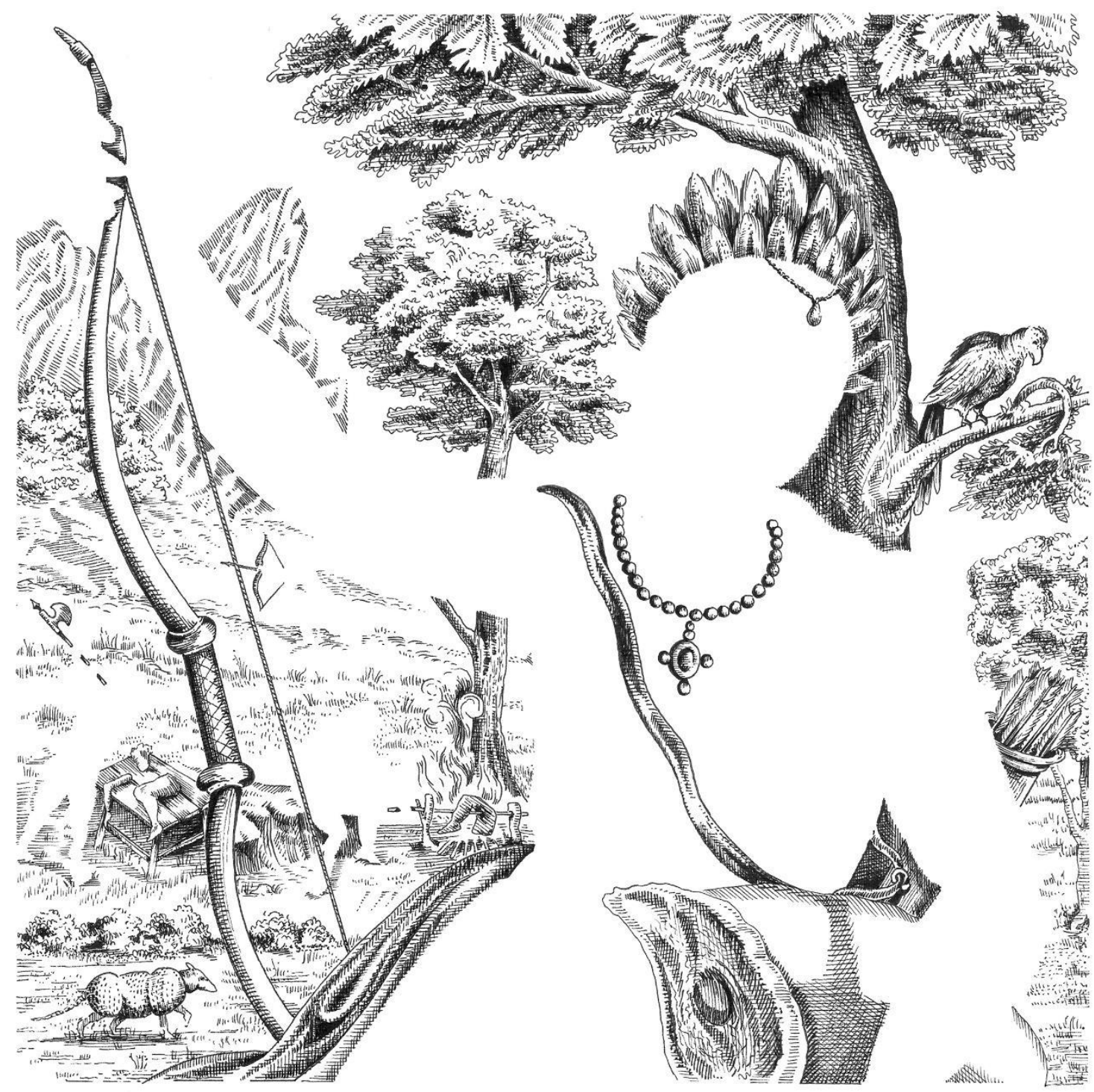

Serie "El cuerpo alegórico de América" \#02 (2017) Paola Monzillo

Dibujos en tinta pigmentada sobre papel de celulosa $300 \mathrm{gr} ., 24 \times 32 \mathrm{~cm}$.

Esta traslación de intereses, naturalmente, estuvo combinada con otro proceso identificado con una 'racionalización' de sus mecanismos que, si bien no considerados aún como instrumentos apriorísticos, si han sido identificados y catalogados profusamente. Para alcanzar ese último estadio pendiente todavía restará analizar los detalles de esta evolución última de la construcción ficcional, tarea que se resumirá en los siguientes párrafos.

La construcción ficcional ha presentado en tiempos recientes una importante transformación, de lo mítico y lo épico a lo icónico y lo temático, en la que nuestro continente juega un papel importante. En particular la 'América' del norte, como dominio de 'lo icónico' y campo para el surgimiento de 'lo temático'. Pero también Latinoamérica, como espacio de mestizaje de la visión europea de 'lo icónico cultural' y la estadounidense de 'lo icónico cotidiano' (the american way of 
life).

En un posible recorrido histórico y sincopado por 'lo temático' del nuevo al viejo continente podemos descubrir similitudes y procesos comunes, 'iluminando' también diferencias bastante drásticas de comportamiento cultural. Más allá del razonamiento evidente de que cada cultura poseerá un acercamiento diferente a este tema, convendremos en realizar una simplificación hipotética también innegable. Sin perjuicio del seguro interés que representaría el estudio de dicho acercamiento en la cultura de Oriente, de la vasta África o del subcontinente indio, hay dos que son los que para nosotros han resultado (y resultan hoy) más determinantes. Desde nuestra condición de americanos, la historia cultural europea ha estado presente desde la conquista española y portuguesa, naciones con las cuales compartimos lengua. Posteriormente, la cultura decimonónica del continente sufrió el fuerte influjo de la intelectualidad francesa e inglesa (y en menor medida alemana) por la vía de las publicaciones y la divulgación científica y artística. Contemporánea y posteriormente, las oleadas de inmigrantes, esta vez principalmente españolas e italianas, pero también de polacos, rusos y otras variadas nacionalidades contribuyeron a una multiculturalidad mestiza de "lo europeo'. Esta inmigración se solaparía con la otra, la de los que huyendo de los conflictos bélicos y sus miserias, se echarían a la mar en busca de 'hacer la América'.

Para la segunda mitad del Siglo XX ya la influencia norteamericana sería patente, como expresión de aquella nación nueva pero exitosa, en la cual un sueño de mejora instantánea en la calidad de vida era posible. Un aparato propagandístico basado entre otras cosas en la cinematografía comenzó a inclinar la centralidad del mundo para los latinoamericanos. Especialmente para los países del norte de Latinoamérica, Estados Unidos comenzó a ser un modelo de referencia, generando con el tiempo (ya en el nuevo siglo) un reflejo de seducción en el norteamericano que se expresa en la caricatura de 'lo latino'. Para los del Cono Sur americano, por el contrario, tanto una u otra imagen continúa hasta hoy generando resistencias, siendo la ascendencia cultural europea un tesoro muy bien guardado.

Pero más allá de todo esto, cabe preguntarnos si es posible desprender la evolución última de lo mítico en Latinoamérica a partir de las evidencias europeas y norteamericanas. Latinoamérica no posee, como es natural, el aplastante peso de la historia cultural que posee Europa. Por otro lado tampoco domina el desprejuicio, la ironía ni el 'espectáculo' como lo hace Estados Unidos.

Sin embargo, una amalgama de especificidades operan como soporte de las anteriores influencias, en parte contradictorias y en parte complementarias. Esta amalgama es sobre la que se vuelve más adelante y que, como se verá, será razón y sentido de nuestra particular visión de la temática, evolucionando en una también particular visión de la disciplina. 


\section{Relato y territorio: Hacia la narración como práctica territorial}

Con la frase "Innumerables son los relatos del mundo" abría Roland Barthes, su a la postre célebre artículo "Introducción al análisis estructural del relato" (1966). Esta afirmación, inocente en apariencia, no hacía más que entreabrir la puerta de una dimensión que había permanecido oculta durante mucho tiempo: la conciencia del valor del relato para la construcción de la existencia humana. Su omnipresencia, no era más que la demostración última de cómo este constituía una de las categorías centrales del conocimiento que los humanos utilizamos para comprender y ordenar el mundo. Entiéndase además que la afirmación inicial de Barthes no debe considerarse de manera simplificada. No son innumerables únicamente los relatos que cuentan, que explican el mundo, sino que son innumerables los relatos que lo construyen; las historias que elaboramos y reelaboramos para resignificar experiencias, para mediatizar nuestra percepción de las cosas.

En una dramática simplificación diremos que la puesta en valor del relato, iniciada simbólicamente en este trabajo de Barthes, dio paso a una serie de estudios teóricos y compendió otros anteriores, que desplegaron una gama de conceptos y dieron a luz sub disciplinas relacionadas. Entre otros el 'dialogismo y las polifonías' (Bajtín, 1936), la 'intertextualidad' (Kristeva, 1997), 'interdiscursividad' (Segre, 1984), 'intermedialidad' (Plett, 1991) y transmedialidad' (Guarinos, 2007), la 'transversalidad' y la 'migración semiótica' (Eco, 1965) y la 'Narratología' (Todorov, 1969). Todos/as ellos/as, en conjunto con las tradicionales herramientas literarias, se vislumbran como instrumentos imprescindibles de indagar de cara a una posible aplicación disciplinar. Naturalmente que el ámbito de este documento no alcanzará más que a postularlo.

Pero si lo anterior es el compendio del nuevo acercamiento teórico al relato, tan o más imprescindible resulta el nuevo acercamiento pragmático: el 'storytelling' (Salmon, 2010). Este constituye la versión protocolizada de la aplicación del relato a una multiplicidad de disciplinas y campos. Como todo protocolo posee una serie de conocimientos sistematizados que se han transformado en rutinas concretas, que se intentan desentrañar de manera de poder evaluar una aplicación específica en las disciplinas del territorio. Con antecedentes tan disímiles como el folclore norteamericano y los clubes de lectura de la 'Generación Beat' el 'storytelling' desembarcó a principios de los noventa en el management empresarial y de allí viajó a las estrategias de manejo de los grandes organismos internacionales. En adelante, la apropiación de la herramienta por los 'gurús del marketing' lo universalizó en ámbitos tan disímiles como la política y los global media. Como colofón de este proceso varios intentos se han efectuado en su aplicación a las disciplinas del territorio, en particular desde el mundo de la planificación prospectiva y el manejo de escenarios, pero también desde acercamientos teóricos singulares en las vanguardias arquitectónicas de las últimas décadas ${ }^{3}$.

El grueso de lo expresado hasta ahora se ha centrado en uno solo de los hemisferios del relato, el del mundo narrado. Como hemos visto, el relato es una

\footnotetext{
${ }^{3}$ Ver: (Coates, 2012); (Potteiger - Purington, 1998); (Giuliani - Hoffmann, 2014, 2015, 2016)
} 
construcción interpersonal e interhistórica de un 'mundo ficcional alternativo' que se opera mediante el contraste, la complementación y la absorción del mundo real. Este último se encuentra fuertemente tensionado por una serie de emergencias, que tratamos someramente en los primeros puntos, y serán las que enriquecerán la historia y, en cierta medida, el discurso narrativo en el método que se propondrá. Este discurso su vez, se encuentra fuertemente condicionado por una estructura que ha sido analizada y sistematizada en profundidad en el último medio siglo, además de inmerso en una realidad temporal (un 'espíritu de la época') del cual no puede escapar, y que establece características preferidas (géneros, formatos, etc.) por sobre otras que son menospreciadas, han sido olvidadas o superadas.

En virtud de esto, en los siguientes párrafos se hará foco por un breve lapso de tiempo en el otro de estos hemisferios, el del narrador, como manera de recordar (antes de seguir adelante) en qué medida reside en él el alma del relato. Si bien las funciones del relato que se han enumerado antes constituyen en cierta medida el objetivo, el pulso del narrador, se atenderá aquí específicamente en las particularidades del rol de contar.

Como también resumimos fugazmente al citar la historia del 'storytelling', el rol de contar se ha socializado hoy a diversas actividades como consecuencia de la generalización del 'contar historias' como método de convencimiento, estrategia de management e instrumento de propaganda, entre otras tantas funciones. Los contadores de historias abundan, así como abundan los soportes y los medios en que estas se prodigan. La propia literatura, el reducto último del relato, ha anunciado en el pasado siglo la 'muerte del autor' (Barthes, 1968) (Foucault, 1968) como entidad individual para dar nacimiento a la escritura como evento colectivo, y posteriormente colaborativo. Sin embargo, persiste aún hoy el contar como expresión de un saber específico, que requiere un know how que ha sido a su vez profusamente sistematizado. No nos necesitamos remontar a la retórica aristotélica para atestiguarlo, ni a los posteriores tratados medievales $\mathrm{y}$ renacentistas, sino que alcanza con limitarnos a los (modestos) manuales contemporáneos de 'storytelling', a las cotidianas escuelas de argumentación, a los (usualmente bizarros) cursos de discurso público, a los talleres de escritura creativa. Contar, literaria u oralmente, requiere un método y hay innumerables teorizaciones y materializaciones acerca de dicho método.

La contracara de esta mecánica sistematización y de esta aparente democratización del contar es su propia tradición histórica. El contar también es un don, una práctica basada en el carisma, la información, la memoria, la habilidad retórica y el aprendizaje práctico. Como tal no todo el mundo lo posee, y de entre quienes lo hacen, tampoco se da en igual medida. No en vano, mucho antes de la notoriedad del escritor favorecida por la circulación de la impresión tipográfica, mucho antes de la fama del director de cine generada tempranamente por Hollywood, el 'aura' del contador oral era una de sus cualidades principales.

En todos los pueblos antiguos, en todas las culturas, desde las ancestrales, la figura del contador de historias constituye una imagen de tintes mágicos, vinculada a la religión, a los poderes sobrenaturales, un ser especial sobre la que no se aplicaban las reglas del común de los ciudadanos. Con incontables 
denominaciones, un mismo personaje se repite en diferentes regiones geográficas y diferentes tiempos.

Los 'griots' o 'djeli' del África Occidental cantan aún hoy sus historias en formato de alabanza, intercalando un amplio repertorio de saberes populares e historias estandarizadas con sus propias improvisaciones. Los 'escaldos' eran los poetas guerreros vikingos que integraban, en la Edad Media, la Corte de los reyes escandinavos. Sus composiciones caracterizadas por el verso aliterativo excedían la pura poesía para constituir crónicas de actualidad y testimoniar los sucesos históricos. Los 'bardos' irlandeses y galos asumían todavía una función más compleja. Además de transmitir la historia comunitaria oficiaban como mensajeros, embajadores de diferentes pueblos, almacenando mediante la oralidad las memorias oficiales (incluso legales y jurídicas) y preservando las genealogías de sus gobernantes. Su amplio conocimiento de códigos y cifrados ha hecho inclusive que se especule con su trabajo en la conservación y transmisión de mensajes secretos. Los 'trovadores' y 'juglares' representan la segregación social de esta práctica en la Europa medieval. Los primeros, de origen nobiliario mayormente, creaban obras centradas en la peripecia amorosa, pero que incluían también la política y en general, su propia visión del mundo. Los segundos eran 'simplemente' intérpretes (músicos y cantantes) que además de desempeñarse en las cortes y festividades de la nobleza, llevaban su arte por entre los pueblos, cantando y contando a los habitantes, muchas veces a cambio de comida y alojamiento. En el subcontinente indio el 'gurú' es el iniciador, quien relata e instruye al principiante en la vida espiritual, pero también quien ofrece consejos y relata las enseñanzas de los libros sagrados.

Finalmente, América posee también un vasto arsenal de 'contadores', desde las civilizaciones precolombinas más desarrolladas a las tribus nómades que habitan en lo profundo de la espesura amazónica. Ejemplo de estas últimas, particularmente interesante, es la figura del 'hablador' retratada por Mario Vargas Llosa en el libro homónimo (1987) En él se relata el misterio y seducción provocado en la tribu machigüenga de la Amazonia peruana por un extraño personaje que se traslada por la selva narrando historias y ofreciendo crónicas de lugares lejanos. 


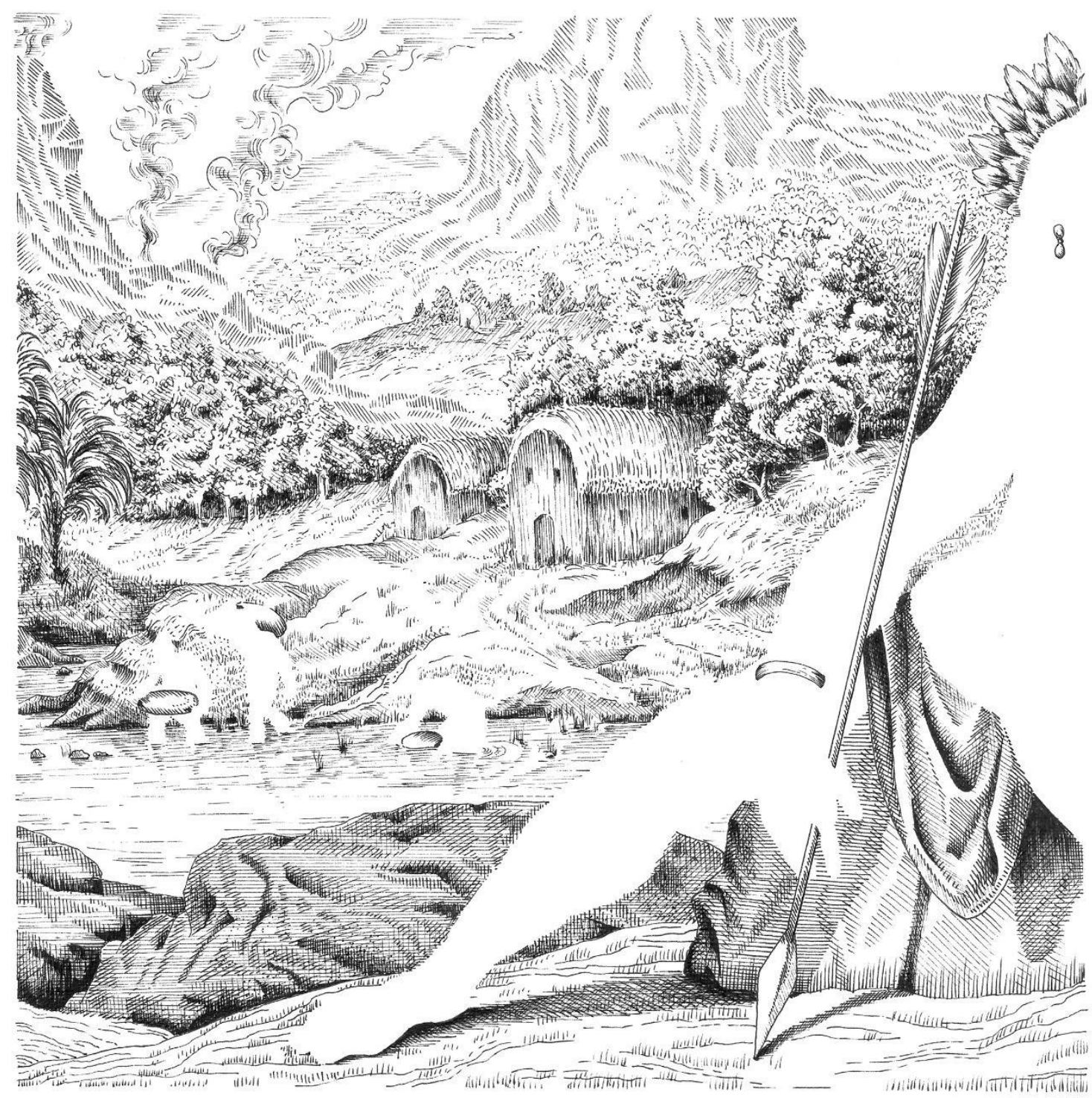

Serie “El cuerpo alegórico de América” \#03 (2017)Paola Monzillo

Dibujos en tinta pigmentada sobre papel de celulosa $300 \mathrm{gr} ., 24 \times 32 \mathrm{~cm}$.

En este sentido se deberá reservar para los puntos finales el desafío de esbozar la combinación de estas dos perspectivas del narrador, del productor del relato. Por un lado la perspectiva de lo cotidiano, de lo mínimo, pasible de ser expresado por cualquiera y en cualquier circunstancia. En cierta medida una capacidad de construcción bottom-up del relato, con intereses, preocupaciones y registros múltiples y diversos que deberá ser incluida en una línea argumental más amplia. Por otro lado la perspectiva histórica del 'contador': referencial, productora de sentido, genealógica y, por qué no, algo mágica. Ineludiblemente estructurada en un formato top-down, será esta la que organizará la estructura general de la narración, la que construirá el esqueleto de la historia y el discurso narrativo y quién, en cierta medida, echará a andar el relato liberándolo para su reproducción y complementación por intermedio de múltiples narradores territoriales. 


\section{América: mundos dentro de mundos}

El interés global a propósito de la construcción de imaginarios y la vigencia del relato, adquiere además, en nuestro continente, un énfasis bastante particular. $\mathrm{Su}$ condición de territorio de reciente 'invención' (O'Gorman, 1958), de dimensiones inusitadas y especificidades dispersas y variadas, contribuye a cierta predisposición territorial a la ficción. El binomio escala-novedad ha operado desde la conquista americana como un elemento productor de ficciones, en la medida en que un territorio liso se comenzaba a estriar mediante las expediciones de conquista y, posteriormente, las transformaciones vinculadas a la voracidad de las actividades productivas-extractivas.

Estas a su vez irían encontrando espacios naturales de gran especificidad, verdaderos microclimas y paisajes fantásticos, que reproducirían y propagarían la idea de la existencia de misterios no descubiertos. Si bien estas dinámicas están hoy lejanas en el tiempo, la pulsión descubridora ha migrado a otras actividades humanas (como por ejemplo el turismo) y se ha conservado firmemente el aura de América como continente inexplorado, exótico y de misterios inusitados. Esta predisposición ficcional ha sido entendida hace tiempo por los intelectuales y/o hacedores de variadas disciplinas, en particular todas aquellas vinculadas a las expresiones artísticas. Posiblemente esto se deba a la falta de una presión racionalizadora, inherente a las disciplinas técnicas y científicas. Sea cual sea la razón, la evidencia muestra que la plástica, la música, la cinematografía y especialmente la literatura han aprovechado esta especificidad y han hecho de esta, aunque sea por períodos, una de sus cualidades distintivas.

Sumado a esto hay que citar su innata condición de territorio relatado, a través de la oralidad y especialmente, la escritura. La palabra escrita posee en nuestro continente, como ha establecido Rama (1988), un poder inusitado desde la llegada de los conquistadores, y sus consecuencias son evidentemente rastreables hasta la actualidad. Desde estas constataciones es que la posibilidad de una aplicación operativa del relato (y sus instrumentos de batalla como el 'storytelling') a las disciplinas del territorio pueda constituir en nuestro continente un verdadero laboratorio exploratorio, naturalmente con sus particularidades en el territorio uruguayo y en los demás sub ámbitos que se podrían reconocer.

\section{La búsqueda de un nuevo protocolo de trabajo.}

Habiendo hecho un sintético recorrido por las emergencias contemporáneas que se entiende habilitan esta transformación operativa, por los antecedentes de la construcción ficcional y el relato, y habiendo presentado resumidamente el recorte territorial de aplicación preferente, solamente resta presentar un menú resumido del trabajo que se habrá de realizar en búsqueda de una nueva metodología de trabajo que contenga las cualidades y características distintivas que se han detallado antes. 
En primer lugar, corresponde fijar la función que en esta nueva metodología deberían asumir las tres categorías estudiadas: paisaje, construcción ficcional y relato. El paisaje es entendido y deberá operar como contexto físico complejo, contexto cultural e histórico, e integrador de emergentes, aprovechando su característica ambigüedad ya enunciada. La ficción estará llamada a actuar desde su poder, accesibilidad, y economía de recursos, siendo la herramienta conectiva entre un paisaje real y un paisaje imaginario que, mixturados generan la posibilidad y pertinencia de un paisaje futuro. El relato, por su parte, será vehículo de la ficción, guardando determinadas lógicas y utilizando determinadas estructuras procedimentales, que un estudio más profundo deberá establecer y catalogar.

En este sentido convendrá plantear las categorías estructurales literarias que se entienden aplicables y necesarias, así como su posible interacción procedimental. Entre ellas simplemente se listarán: la reflexión acerca de los hemisferios de narrador y mundo narrado, la justificación de la historia, relato y narración como elementos obligatorios del proceso planificador / creador, el estudio y establecimiento de las claves para la construcción de la historia y del discurso narrativo, la reflexión a propósito de 'la condición del acto narrativo, y la traslación del debate y transferencia conceptual acerca de los roles de autor y lector (emisor-receptor) de un relato a la construcción y gestión territorial.

Finalmente se deberá abordar la configuración de un kit de instrumentos particulares para un posible manual de operatividad. El uso de herramientas literarias: géneros y subgéneros preferidos, la construcción de la estructura lingüística del discurso y las figuras de significación o tropos, de gran productividad para el relato territorial, puesto que permiten la traslación significante entre elementos conocidos (reales o ficcionales) colectivizando la tarea narrativa. En dicho contexto, la 'intertextualidad' ya nombrada será interpelada en relación a una 'América omnipresente', fuente de referencias latentes y subliminales.

El 'storytelling' deberá ser también objeto de análisis para incorporar sus herramientas. Así, se deberán integrar las distintas metodologías aportadas por sus principales referentes teóricos: el uso de 'historias catalogadas' (Denning, 2000, 2004) y la conformación de patrones narrativos; la 'antenarración' (Boje, 1991) y su estudio, la 'antenarratología', y la productividad de la 'story', versión condensada del relato, que se ha generalizado como formato preferido de comunicación de masas para la política, los mass media, el comercio y la propaganda. Naturalmente se incorporarán en el mencionado manual las exploraciones interiores a la disciplina, en particular la provocación implícita del 'relato koolhaasiano' (Koolhaas, 1978), el relato en formato 'cuento de hadas', relato gráfico 'de base diagramática' y las 'historias del paisaje y la arquitectura narrativa' (Coates, 2012), todos productos incipientes o parciales, pero de gran posibilidad productiva. 


\section{La escala y sus variantes, una aplicación a la creación arquitectónica y el paisaje de pequeña escala}

Nuestra experiencia formativa nos lleva (una vez más) a preguntarnos en qué medida estas reflexiones que se han esbozado son aplicables a contextos de escala y complejidad menor, y si el método tentativo que se ha arriesgado posee aplicación, en particular, en el ámbito arquitectónico y el micro paisaje.

Como es natural, dicho cuestionamiento implica el ajuste de una estructura investigativa diferente, sin embargo, es dable pensar que muchas de las problematizaciones de base y muchas de las respuestas temáticas son, en cierta medida a-escalares.

Seguramente se deba considerar que la consecuente reducción de escala de los objetos considerados debería arrastrar idéntica reducción de las herramientas de trabajo. Aceptada como válida esta homotecia se habría de considerar si la metáfora, como escala mínima de la creación de sentido narrativo (por oposición a la propia narración), no debería pasar a ocupar el lugar protagónico que para la escala paisajística y territorial se ha otorgado al relato. Sin perjuicio de ello, la aplicación de este último con seguridad se descubra necesaria todavía en determinados casos en que la complejidad de la creación arquitectónica, el perfil cultural, o la naturaleza ficcional de la misma así lo reclame.

Relato o metáfora constituyen armas imprescindibles contra el ensimismamiento propio de la práctica cotidiana, contra la omnipresente inspiración del arquitecto-artista y el mecanicismo funcional derivados de la modernidad histórica, contra la imitación, referencia y aplicación de modelos de la posmodernidad, contra la mera recurrencia actual de mecanismos enfocados en el azar de 'la idea'. Ellos poseen con seguridad la ventaja de su ideación previa a la concepción del proyecto y, como tales, sirven para guiar la búsqueda proyectual, señalando caminos, direcciones, avalando o refutando opciones conceptuales, estéticas y materiales. Tanto el relato como la metáfora se edifican sobre la existencia de unas 'líneas argumentales' con contenido semántico que, en la medida que son 'compartidas' por el destinatario (cliente o comitente), derriban las barreras de la selección amparada en 'el gusto', 'la moda' o el azar.

El argumento constituye, además del inicio, la razón, el sentido y el plan de viaje, la propia explicación del proyecto arquitectónico - paisajista, ocupando el lugar de la anterior y vergonzosa 'memoria proyectual'. Anterior puesto que, pese a las transformaciones del último siglo en los acercamientos a la tarea del proyecto arquitectónico, continúa extrañamente vigente. Vergonzosa porque, desde su propia denominación, parece reconocer la posición (estrictamente) dependiente del creador frente a la eventualidad del azar, ocupándose (tan sólo) de reconstruir a posteriori los caminos que llevaron a la configuración final del producto. 


\section{Referencias}

Bajtín, M. (1986) [1936] Problemas de la poética de Dostoievski. México D.F., México: Fondo de Cultura Económica.

Barthes, R. (1968). Introducción al análisis estructural del relato En: Silvia Niccolini (Comp.). (1977). El análisis estructural. Buenos Aires, Argentina: Centro Editor de América Latina. Original: (1966). "Introduction à l'analyse structurale des récits”. Revue Communications, № 8, pp.65 y ss.

Boje, D. M. (1991). “The Storytelling Organization: A Study of Story Performance in an Office-Supply Firm", Administrative Science Quarterly, Vol. 36, Nro. 1, pp: 106-126.

Brooke-Hitching, E. (1996). The Phantom Atlas: the greatest myths, lies and blunders on maps, Londres, Inglaterra: Simon \& Schuster.

Calvino, I. (2017). Las ciudades invisibles. Madrid, España: Ediciones Siruela.

Coates, N. (2012). Narrative Architecture, Chichester, Inglaterra: John Wiley \& Sons Ltd.

De Tocqueville, A. (2015). Atlas de las ciudades perdidas. Madrid, España: Geoplaneta.

Denning, S. (2000). The Springboard: How Storytelling Ignites Action in Knowledge-Era Organizations. Boston, USA: Butterworth Heinemann.

Denning, S. (2004). Squirrel Inc.: A Fable of Leadership through Storytelling. San Francisco, USA: Jossey-Bass / John Wiley \& Sons.

Eco, U. (1968). Apocalípticos e integrados. Barcelona, España: Lumen.

Foucault, M. (1968). Las palabras y las cosas. Una arqueología de las ciencias humanas. Buenos Aires, Argentina: Siglo XXI Editores.

Giuliani, F. y Hoffmann, M. (eds.). (2014). Fairy Tales: When Architecture tells a story. Volume 1. New York, USA: Blank Space.

Giuliani, F. y Hoffmann, M. (eds.). (2015). Fairy Tales: When Architecture tells a story. Volume 2. New York, USA: Blank Space.

Giuliani, F. y Hoffmann, M. (eds.). (2016). Fairy Tales: When Architecture tells a story. Volume 3. New York, USA: Blank Space.

Guadalupi, G. y Manguel, A. (2004). Breve guía de lugares imaginarios. Madrid, España: Alianza Editorial. 
Guarinos, V. (2007) "Transmedialidades: el signo de nuestro tiempo". Comunicaciones: Revista Internacional de Comunicación Audiovisual, Publicidad y Estudios Culturales, Volumen I, Número 5, pp:17-22.

Koolhaas, R (1978). Delirious New York: A Retroactive Manifesto for Manhattan. New York City, USA: Oxford University Press.

Kristeva, J. (1997). "Bajtín, la palabra, el diálogo y la novela”. En: AA.VV.- Navarro, Desiderio (ed.). (1997). Intertextualité. Francia en el origen de un término y desarrollo de un concepto. La Habana, Cuba: UNEAC - Casa de las Américas.

Lanni, D. (2016). Atlas de los lugares soñados. Madrid, España: Geoplaneta.

Le Carrer, O. (2015). Atlas de los lugares malditos. Madrid, España: Geoplaneta.

Middleton, N. (2016). Atlas de países que no existen. Madrid, España: Geoplaneta.

O’Gorman, E. (1958). La invención de América. México D.F., México: Fondo de Cultura Económica.

Plett, H. (ed.). (1991). Intertextuality. Berlín-Nueva York, Alemania-USA: Walter de Gruyter.

Potteiger, M. - Purington, J. (1998). Landscape Narratives: Design Practices for Telling Stories. New York, USA: John Wiley \& Sons Ltd.

Rama, Á. (1998). La ciudad letrada, Montevideo, Uruguay: Editorial Arca.

Salmon, C. (2010). Storytelling. La máquina de fabricar historias y formatear las mentes. Barcelona, España: Ediciones Península.

Schalansky, J. (2011). Atlas de islas remotas. Barcelona, España: Capitán Swing Nórdica Libros.

Segre, C. (1984). Teatro e romanzo. Due tipi de comunicazione letteraria. Torino, Italia: Einaudi Editore.

Vargas Llosa, M. (1987). El hablador. Barcelona, España: Seix Barral.

\section{Ilustraciones}

Las ilustraciones que acompañan el presente ensayo constituyen la serie "El cuerpo alegórico de América" (2017), de la arquitecta y artista plástica Paola Monzillo. La serie se compone de dibujos realizados a partir de grabados de los siglos XVI y XVII, producidos y distribuidos en Europa durante la expansión colonial, en los que se representa el continente americano en formato de alegoría (Adriaen Collaert y Marten de Vos, 1551; John Stafford, 1625-1635; Johann Sadeler 
y Dirck Barendsz, 1581). Estos grabados formaron parte de un creciente cuerpo de informaciones que mapearon los diferentes continentes en relación con las creencias y valores imperantes en la Europa de la época. Las copias en dibujo reproducen con fidelidad los escenarios de fondo, pero dejan en blanco, deliberadamente, los espacios ocupados por los cuerpos humanos en la escena. 